\title{
Perioperative outcomes of laparoendoscopic single-site extracorporeal versus intracorporeal cystectomy for benign ovarian cysts: a retrospective cohort study based on propensity score matching
}

\author{
Wenwei Tan^, Shuai Tang, Yuanyang Yao, Yuan Deng, Kuiyan Zhong, Zhiqing Liang, Li Deng, Yanzhou Wang \\ Department of Obstetrics and Gynecology, The First Affiliated Hospital (Southwest Hospital), Army Medical University (Third Military Medical \\ University), Chongqing, China \\ Contributions: (I) Conception and design: Y Wang, L Deng, W Tan; (II) Administrative support: Y Wang, L Deng; (III) Provision of study materials \\ or patients: S Tang, Y Yao, Z Liang; (IV) Collection and assembly of data: W Tan, Y Deng, K Zhong; (V) Data analysis and interpretation: W Tan; (VI) \\ Manuscript writing: All authors; (VII) Final approval of manuscript: All authors. \\ Correspondence to: Li Deng; Yanzhou Wang. Department of Obstetrics and Gynecology, The First Affiliated Hospital (Southwest Hospital), Army \\ Medical University (Third Military Medical University), Chongqing 400038, China. Email: denglitmmu@163.com; w.y.z@foxmail.com.
}

Background: Ovarian cysts are the most common gynecological disease, and laparo-endoscopic single-site (LESS) cystectomy is a popular surgical procedure. A new laparoscopic technique combining the advantages of LESS surgery and open surgery has been introduced to treat large ovarian cysts. To our knowledge, no previous research has compared LESS-extracorporeal (LESS-E) cystectomy to LESS-intracorporeal (LESS-I) cystectomy. This study compared the perioperative results of LESS-E cystectomy and LESS-I cystectomy in the treatment of benign ovarian cysts.

Methods: Two hundred eighty-eight cases of cystectomy from our institutional database were retrospectively reviewed. 1:1 propensity score matching (PSM) was performed to minimize bias due to any imbalanced baseline features between the 2 groups, which were matched in terms of age, body mass index, and the largest diameter of ovarian cysts. Seventy-nine cases were then selected from each group, and the perioperative outcomes of the 2 cohorts were analyzed.

Results: The mean (standard deviation) largest diameter of ovarian cysts was $8.30(3.56) \mathrm{cm}$ in the LESS-I group and $9.14(3.15) \mathrm{cm}$ in the LESS-E group ( $\mathrm{P}=0.118)$. No statistically significant difference was found between the 2 groups in terms of estimated blood loss, postoperative hemoglobin decline, postoperative pain in 24 hours, postoperative hospital stay, and total hospital costs $(\mathrm{P}>0.05)$. However, the mean operation time of the LESS-E group was shorter than that of the LESS-I group (85.01 vs. 104.25 minutes; P=0.001). Additionally, the spillage rate of the LESS-I group was significantly greater than that of the LESS-E group ( $46.8 \%$ vs. $17.7 \% ; \mathrm{P}<0.001)$. The mean pain scores at 6 postoperative hours as measured by a visual analogue scale were significantly greater in the LESS-I group than the LESS-E group (3.85 vs. 3.37; $\mathrm{P}=0.016$ ).

Conclusions: LESS-E cystectomy is a safe and feasible approach with a shorter operation time and lower spillage rate than LESS-I cystectomy.

Keywords: Laparoendoscopic single-site surgery; extracorporeal cystectomy; intracorporeal cystectomy; perioperative results

Submitted Sep 23, 2021. Accepted for publication Nov 29, 2021.

doi: 10.21037/atm-21-5625

View this article at: https://dx.doi.org/10.21037/atm-21-5625

^ ORCID: 0000-0002-0772-9596. 


\section{Introduction}

Ovarian cysts are the most common gynecological disease and frequently appear in females of reproductive age (1). According to different types of ovarian cysts, the treatment methods are also different, including observation, medicine treatment, aspiration and surgery. For patients with surgical indications, open surgery or laparoscopic surgery are optional. At present, minimally invasive surgery is the mainstream surgical method for the treatment of benign ovarian cysts, which has a number of undeniable benefits over laparotomy, including less postoperative pain, fewer postoperative complications, a faster recuperation time, and a shorter hospital stay (2-4).

In recent decades, surgeons have strived to reduce the size, number, and placement of incisions to minimize abdominal wall trauma, and with the development of optical devices, surgical instruments, and ports, laparoendoscopic single-site (LESS) surgery has become a popular surgical procedure $(5,6)$. LESS surgery has outstanding cosmetic advantages, as the surgical scar is largely concealed within the umbilicus, a natural embryonic orifice (7). Extensive studies have proven the feasibility and security of the LESS surgical procedure in the treatment of benign ovarian cysts (8-16). Schmitt et al. (17) conducted a meta-analysis of 841 patients who underwent LESS and conventional laparoscopy for ovarian cystectomy demonstrated that postoperative pain, operative blood loss, cosmetic results and postoperative complication rates are comparable between both techniques. Kim et al. (18) reported that LESS had fewer ports than conventional group and the postoperative pain was less. Another study (19) showed that the LESS group had a significantly lower postoperative pain score and analgesics requirement compared to the conventional group.

However, large ovarian cyst surgery faces a number of challenges, including technical challenges, a limited operating space for the use of endoscope instruments, and unexpected spillage during Veress needle or trocar insertion (1). A new laparoscopic technique combining the advantages of LESS surgery with those of open surgery has been introduced. After the suction of the fluid contents, the cyst is pulled out through the umbilicus, and the extracorporeal cystectomy is then performed, followed by an inspection of the whole peritoneal cavity and careful irrigation (20-22). The feasibility and safety of such LESS surgery for the treatment of very large ovarian cysts has been proved (22-25). LESSextracorporeal (LESS-E) cystectomy has several advantages, including the ease of switching between extracorporeal and intracorporeal approaches, the low relative risk of spillage, and excellent cosmetic results (22).

As far as we are aware, no previous research has compared LESS-E cystectomy with LESS-intracorporeal (LESS-I) cystectomy. While we found that patients in our hospital with equal diameter of ovarian cysts conducted both surgical procedures. The research question driving this study is: what kind of surgery is more beneficial to patients? A retrospective cohort study based on propensity score matching (PSM) was designed to compare the perioperative results of LESS-E and LESS-I cystectomy in the treatment of benign ovarian cysts. We present the following article in accordance with the STROBE reporting checklist (available at https://dx.doi.org/10.21037/atm-21-5625).

\section{Methods}

288 patients, who underwent LESS cystectomy between August 1, 2016 and October 29, 2019 at The First Affiliated Hospital of the Army Medical University, were retrospectively reviewed in this study. Of these 288 patients, 45 were excluded, as they met 1 of the following exclusion criteria: (I) the pathological results revealed malignant or borderline tumors; (II) a hysteromyomectomy was conducted; (III) the patient was pregnant; or (IV) a bilateral cystectomy was conducted. Of the final 243 patients, 105 patients underwent LESS-E cystectomy and 138 patients underwent LESS-I cystectomy. 1:1 PSM was performed to minimize any bias due to the imbalanced baseline features between the 2 groups, and the 2 groups were matched in terms of age, body mass index (BMI), and the largest diameter of ovarian cysts. Seventy-nine cases from each group were then selected (see Figure 1). All procedures performed in this study involving human participants were in accordance with the Declaration of Helsinki (as revised in 2013). The study was approved by the Ethics Committee of The First Affiliated Hospital, Army Medical University (approval No. KY202024). Individual consent for this retrospective analysis was waived.

\section{Surgical technique}

Both techniques were conducted on a single-access multichannel port with 2 parts, a detachable port cap with 4 access ports (2 $12-\mathrm{mm}$ ports and 25 -mm ports), and a $70-\mathrm{mm}$ retractor component. The patients in both groups were placed under general endotracheal anesthesia and placed in a dorsal lithotomy position. A Foley catheter was 


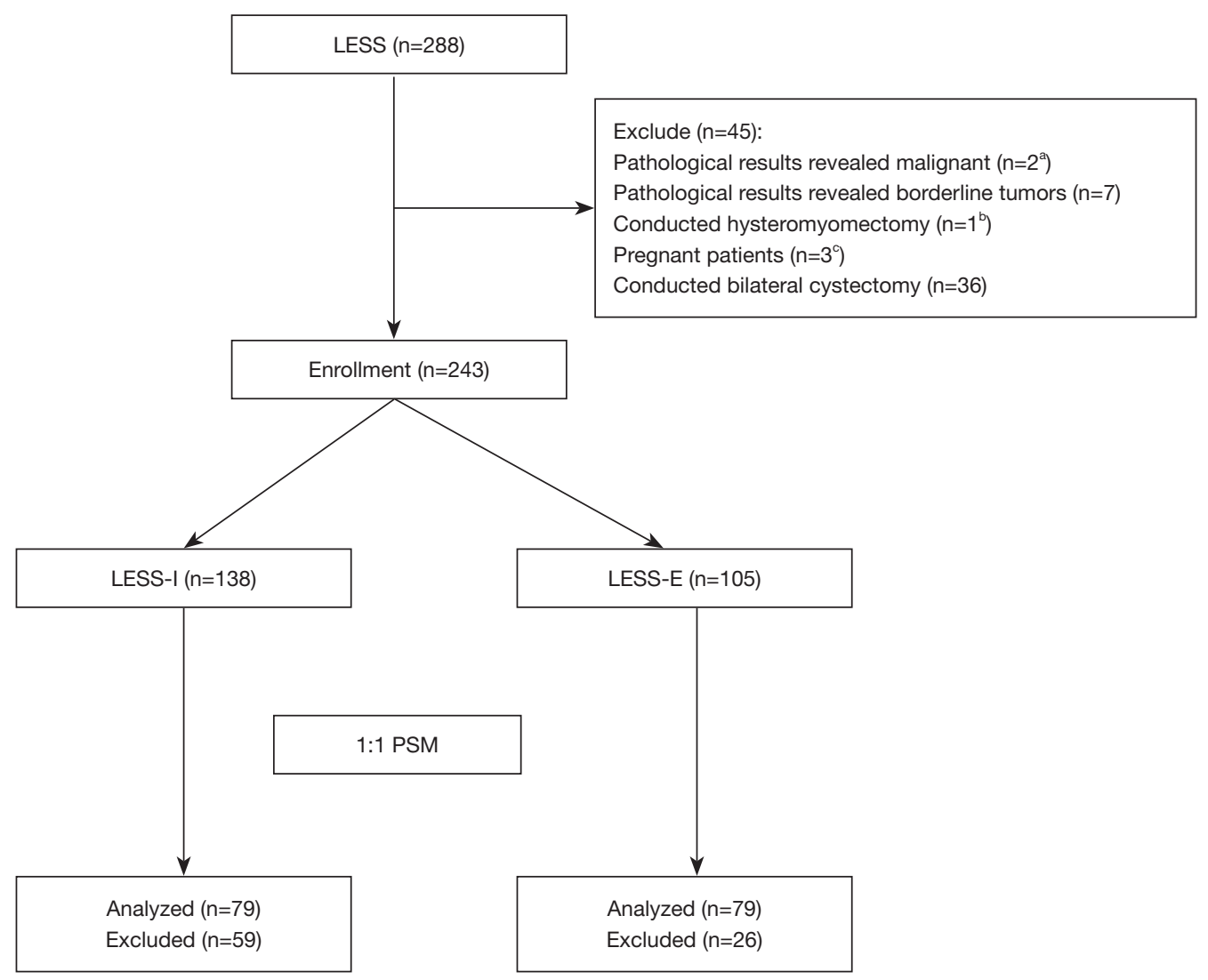

Figure 1 Flowchart of group allocation. ${ }^{\text {a }}, 1$ of the 2 associated with bilateral cystectomy; ${ }^{\text {, }}$, associated with bilateral cystectomy; ${ }^{\mathrm{c}}, 2$ of the 3 associated with bilateral cystectomy. LESS, laparo-endoscopic single-site; LESS-I, LESS-intracorporeal; LESS-E, LESS-extracorporeal; PSM, propensity score matching.

inserted into the bladder, and a uterine manipulator via vaginal access was used for uterine manipulation. A vertical skin incision (ranging from 2 to $2.5 \mathrm{~cm}$ in size) was made, followed by a peritoneal and fascial incision at the midline of the umbilicus. A wound retractor (to which a port cap was affixed) was inserted into the incision. The intraperitoneal pressure of pneumoperitoneum was maintained at $12 \mathrm{mmHg}$. A 10-mm, 30-degree laparoscope was then inserted through the $12-\mathrm{mm}$ port to explore the peritoneal surface, omentum, contralateral ovary, and ovarian cyst. In cases of mild adhesion, the adhesiolysis was performed using conventional laparoscopic instruments through the singleport channel. Subsequently, the mobility of the adnexal mass and the extensibility of adnexal ligaments for delivery through the umbilical incision were evaluated.

The detachable port cap in the LESS-E group was then removed to start the extracorporeal process. After identifying the mass, a purse-string suture was used at the corners of the cystic surface, which was exposed with a wound retractor (see Figure $2 A$ ). The cyst was then punctured through the suture, and a suction tip was used to rapidly aspirate its contents. A Kelly clamp was used to hold the puncture site on the cyst, and pieces of surgical gauze were used to cover the internal edge of the wound retractor to prevent the spillage of cystic content. Upon exteriorization, the ovarian cyst was encircled with wet wide surgical gauze to avoid tissue dryness and extracorporeal spillage throughout the surgery. Next, common surgical instruments were used to completely separate the cystic capsule from the normal tissue as in open surgery (see Figure $2 B$ ). After completing the ovarian cyst enucleation (see Figure 2C), the remaining tissues were remodeled with 3-0 absorbable sutures (see Figure 2D). Upon the completion of the extracorporeal step, the ovary was immediately returned to the abdominal cavity (see Figure 2E). Once the port cap was reset, the laparoscope and laparoscopic devices were inserted, and the abdominal cavity was copiously irrigated with normal saline after 

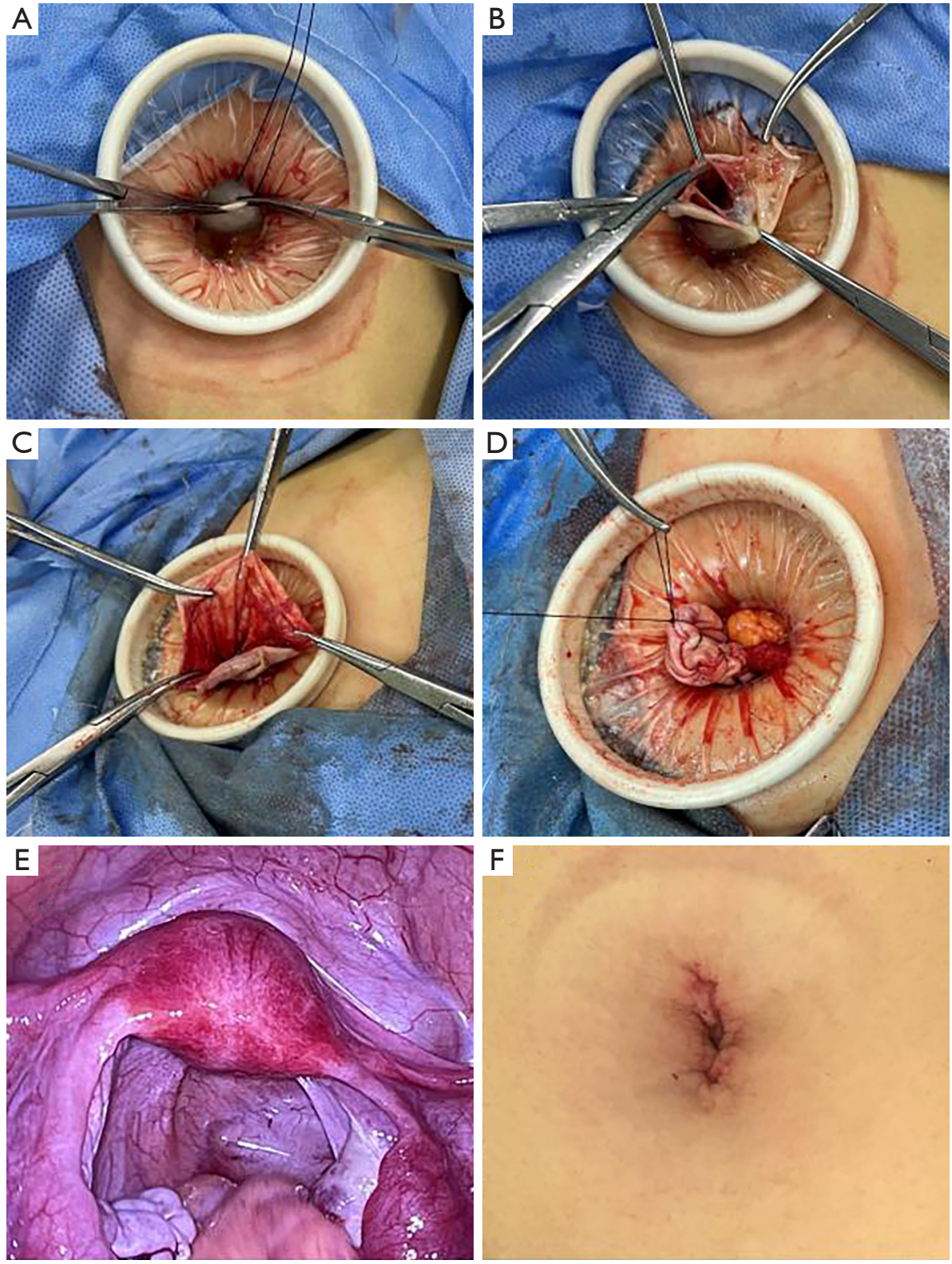

Figure 2 The procedure of LESS-E cystectomy. (A) Exteriorization of the tumor capsule; (B) separation of the cystic capsule and normal tissue; (C) ovarian cyst enucleation was completed; (D) remodeling of remnant ovarian tissues; (E) intra-pelvic appearance after cystectomy; (F) postoperative umbilical wound. LESS-E, laparoendoscopic single-site-extracorporeal.

careful observation for any bleeding foci or pathological findings. The fascia and peritoneum of the umbilicus were closed, layer by layer, with 2-0 absorbable sutures, after which the skin incision was closed with 4-0 absorbable intracutaneous stitches (see Figure 2F).

The procedure used in the LESS-I group was similar to that performed in conventional laparoscopic surgery. After placing the ovary in a specimen bag, laparoscopic enucleation was then performed to prevent intraperitoneal spillage. First, endoshears were used to incise the antimesenteric border of the ovary. Second, after identifying the cyst wall, a bidirectional dissection of the surrounding ovarian cortex was performed using a combination of electrocoagulation, traction, and countertraction, and the sharp and blunt technique. Third, the bed was carefully examined and bleeding areas were safeguarded 
Table 1 Comparison of the standardized differences of each covariate before and after PSM

\begin{tabular}{lccc}
\hline Before and after matching & Age (years) & BMI $\left(\mathrm{kg} / \mathrm{m}^{2}\right)$ & Maximum diameter of cyst $(\mathrm{cm})$ \\
\hline Before matching & & & \\
LESS-E & $27.88 \pm 7.78$ & $21.12 \pm 3.15$ & $10.35 \pm 3.88$ \\
LESS-I & $27.77 \pm 8.19$ & $21.49 \pm 3.12$ & $7.24 \pm 3.04$ \\
Comparison between groups & $\mathrm{F}=0.433, \mathrm{P}=0.917$ & $\mathrm{~F}=0.761, \mathrm{P}=0.384$ & $\mathrm{~F}=7.754, \mathrm{P}<0.001$ \\
Standardized difference & 0.0147 & 0.1180 & 0.8923 \\
After matching & & & $9.14 \pm 3.15$ \\
LESS-E & $28.39 \pm 7.41$ & $21.08 \pm 3.17$ & $8.30 \pm 3.56$ \\
LESS-I & $28.90 \pm 8.77$ & $21.36 \pm 3.11$ & $\mathrm{~F}=0.827, \mathrm{P}=0.118$ \\
Comparison between groups & $\mathrm{F}=2.965, \mathrm{P}=0.696$ & $\mathrm{~F}=0.183, \mathrm{P}=0.573$ & 0.2499 \\
Standardized difference & 0.0628 & 0.0892 & \\
\hline
\end{tabular}

PSM, propensity score matching; LESS-I, LESS-intracorporeal; LESS-E, LESS-extracorporeal; BMI, body mass index.

by cauterization after the ovarian cyst was excised. Fourth, the remaining tissues were remodeled with 3-0 absorbable sutures. Finally, after specimen removal, similar steps were performed to those described above for the LESS-E procedure.

Patient data, including the operative time, cyst content spillage rate, estimated blood loss, postoperative pain, postoperative exhaust time, postoperative out-of-bed time, postoperative hospital stay, final pathology, and demographic information were collected. Any cyst content found in the pelvic cavity after the completion of the cystectomy was defined as positive spillage. The duration of the surgery was timed, starting with the skin opening and ending with the skin closure. Total blood loss during the operation was estimated by deducting the saline used to wash out the abdominal cavity and the total amount of the cyst content from the total volume of fluid aspirated. Postoperative pain was evaluated using a visual analogue scale (VAS) at 6 and 24 hours after the operation.

\section{Statistical analysis}

1:1 PSM was performed using SPSS Statistics 26.0 software. The covariates used in matching included age, BMI, and the largest diameter of the cysts, and the matching tolerance was 0.1 . The mean \pm standard deviation (SD) was used to express continuous variables that conformed to a normal distribution, and t-tests were used for comparisons between the groups; otherwise, the Mann-Whitney test was used, and the results were described as the median [interquartile range (IQR)]. The Fisher exact test or the chi-square test was used to analyze categorical variables. A $\mathrm{P}$ value less than $0.05(\mathrm{P}<0.05)$ was considered statistically significant.

\section{Results}

In this study, 105 patients underwent LESS-E cystectomy and 138 patients underwent LESS-I cystectomy. Using PSM with a matching tolerance of 0.1 , a total of 79 patients in each group were matched. The standardized differences before and after the matching of each covariate are shown in Table 1. Notably, the standardized differences of the covariates after matching were reduced, and the imbalance in distribution of the covariates was decreased.

The characteristics of the selected patients are set out in Table 2. The mean age of patients in the LESS-I group and LESS-E group was $28.90 \pm 8.77$ and $28.39 \pm 7.41$ years $(\mathrm{P}=0.696)$, respectively. The pathological findings between the groups were similar $(\mathrm{P}=0.880)$. A mature cystic teratoma was the most common pathological feature in both groups. The mean (SD) largest diameter of the ovarian cysts was $8.30(3.56) \mathrm{cm}$ in the LESS-I group and $9.14(3.15) \mathrm{cm}$ in the LESS-E group $(\mathrm{P}=0.118)$. There was no significant difference in the characteristics between the 2 groups $(\mathrm{P}>0.05)$.

The perioperative results are set out in Table 3. Rupture of the cyst was observed in 14 of 79 (17.7\%) patients in the LESS-E group, a figure significantly lower than that observed in the LESS-I group of 37 of 79 (46.8\%) $(\mathrm{P}<0.001)$. The mean operation time, calculated from the 
Table 2 Patients' characteristics

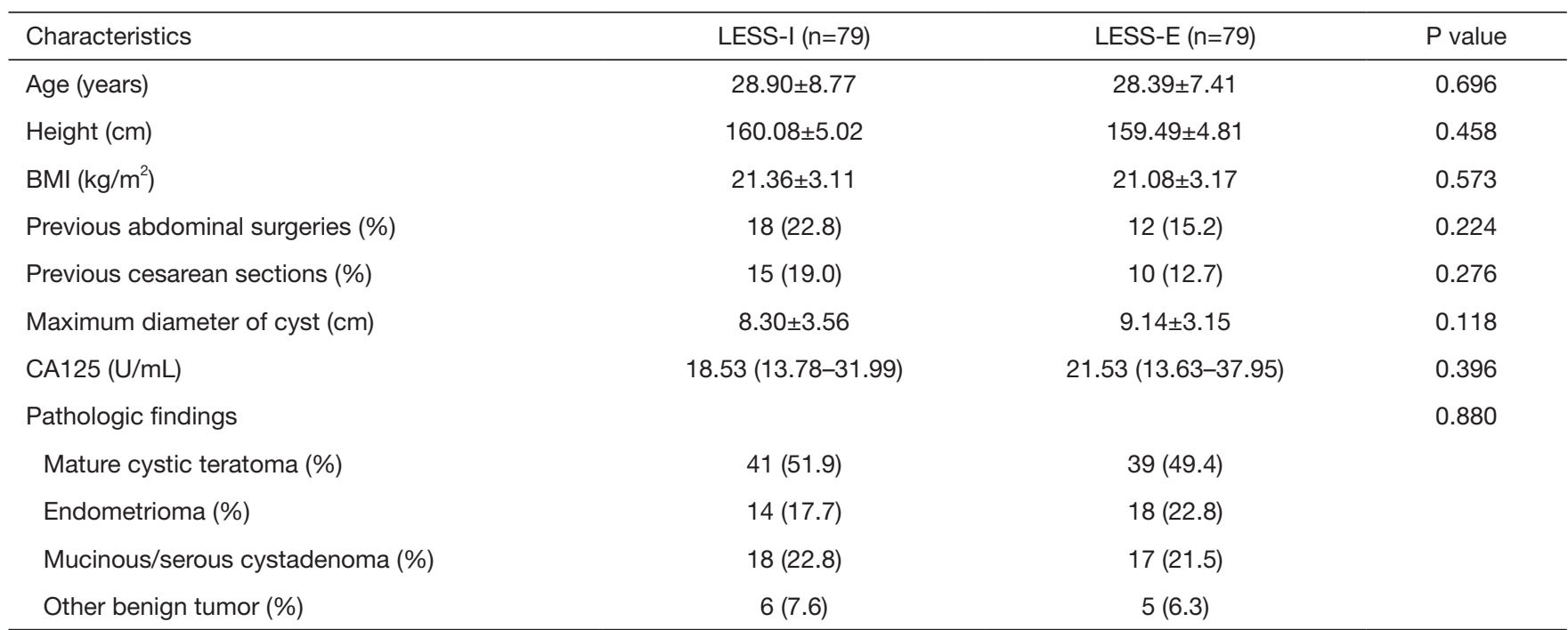

Other benign tumors included simple cyst, paraovarian cyst, corpus luteum cyst, follicular cyst, and ovarian fibroma. Data are presented as mean \pm SD, median (IQR) and $n$ (\%). LESS-I, LESS-intracorporeal; LESS-E, LESS-extracorporeal; BMI, body mass index; CA125, cancer antigen 125 .

Table 3 Comparison of the surgical results and perioperative complications in the 2 groups

\begin{tabular}{|c|c|c|c|}
\hline Variable & LESS-I (n=79) & LESS-E $(n=79)$ & $P$ value \\
\hline Estimated blood loss (mL) & $50[30-100]$ & 50 [20-100] & 0.856 \\
\hline Cyst rupture (\%) & $37(46.8)$ & $14(17.7)$ & $<0.001$ \\
\hline Pelvic adhesion (\%) & $30(38.0)$ & $33(41.8)$ & 0.626 \\
\hline Post operation day & $3.54 \pm 1.13$ & $3.41 \pm 1.42$ & 0.496 \\
\hline Postoperative fever & 3 & 1 & \\
\hline$\Delta \mathrm{Hb}(\mathrm{g} / \mathrm{dL})$ & $1.56 \pm 0.71$ & $1.74 \pm 0.84$ & 0.150 \\
\hline \multicolumn{4}{|l|}{ Postoperative pain scores } \\
\hline Postoperative exhaust time (h) & 18 [13-22] & 18 [13-22] & 0.950 \\
\hline Postoperative out-of-bed time (h) & $15.84 \pm 2.49$ & $15.46 \pm 1.79$ & 0.273 \\
\hline
\end{tabular}

Data are presented as mean \pm SD, median (IQR) and $n(\%), \Delta \mathrm{Hb}$, postoperative hemoglobin decline. LESS-I, LESS-intracorporeal; LESS-E, LESS-extracorporeal.

beginning of skin incision to skin closure, was shorter in the LESS-E group than the LESS-I group [85.01 (27.67) vs. 104.25 (40.54) minutes; $\mathrm{P}=0.001]$. The mean postoperative pain scores at 6 hours after surgery (measured using VAS scores) were significantly lower in the LESS-E group than the LESS-I group [3.37 (1.16) vs. 3.85 (1.31); $\mathrm{P}=0.016]$. There was no statistically significant difference in terms of the estimated blood loss, pelvic adhesion, postoperative hemoglobin decline, postoperative exhaust time, postoperative out-of-bed time, postoperative pain in 
24 hours, postoperative hospital stay, and total hospital costs $(\mathrm{P}>0.05)$.

No intraoperative complications that required treatment occurred in either group. In relation to postoperative complications, 3 patients in the LESS-I group had a fever, and 1 patient in the LESS-E group had a fever. No conversion to laparotomy was needed in the LESS-E group, and no additional trocars were needed in the LESS-I group. In a 3-month follow-up, there was no postoperative fever or incisional hernia in the two groups. And the scar is almost invisible.

\section{Discussion}

To our knowledge, the present study is the first cohort comparison of the LESS-E and LESS-I approaches in the treatment of benign ovarian cystectomy. Both groups successfully completed the operation without conversion to multiport laparoscopic or open surgery. Compared to LESS-I, LESS-E resulted in a lower rate of cystic content spillage $(\mathrm{P}<0.001)$, a reduced operation time $(\mathrm{P}=0.001)$, and decreased VAS scores at 6 hours after surgery $(\mathrm{P}=0.016)$. There was no statistically significant difference in terms of estimated blood loss, postoperative pain in 24 hours, postoperative hemoglobin decline, postoperative hospital stay, and total hospital costs $(\mathrm{P}>0.05)$.

A previous multivariate regression analysis (26) indicated that only the cystectomy procedure and cyst size were significantly and positively associated with inadvertent cyst rupture in the laparoscopic removal of adnexal cysts. Notably, during cystectomy, there is a greater risk of malignancy in bigger cysts, which is accompanied by a risk of iatrogenic spillage of malignant cells. Thus, reducing cystic content spillage is of great significance in decreasing pelvic-abdominal metastasis and patient prognosis (27). In this context, the mean diameter of the cysts in the LESS-I group was comparable to that in the LESS-E group $(8.3 \pm 3.56$ vs. $9.14 \pm 3.15 \mathrm{~cm} ; \mathrm{P}=0.118)$. The spillage rate was dramatically lower in the LESS-E group than the LESS-I group $(17.7 \%$ vs. $46.8 \%$; $\mathrm{P}<0.001)$. This is mainly because the space constraint in the LESS-I group makes instrumentation difficult and cystectomy rupture possible (27). In the LESS-E group, using a Kelly clamp to hold the cyst wall, a purse-string suture to close the puncture hole, and pieces of surgical gauze to cover the inner edge of the wound retractor can reduce cystic fluid leakage during the intracorporeal procedure $(21,24)$. Our results were similar to those of a previous study (28) that compared single-port-access pure laparoscopic surgery (SPA-PLS) with single-port-access hand-assisted laparoscopic surgery (SPA-HALS) for adnexal tumors for which there were 33 cases $(31.3 \%)$ and 4 cases $(10.3 \%)$ of intracorporeal spillage in the SPA-PLS group and the SPA-HALS group, respectively $(\mathrm{P}=0.005)$. Another case-control study (1) compared conventional laparoscopy with single-port assisted extracorporeal ovarian cystectomy in the treatment of benign ovarian cysts found a significantly lower spillage rate in the latter $(69.7 \%$ vs. $8.0 \% ; \mathrm{P}<0.001)$. Kim (20) reported on 22 patients with ovarian cysts diameter $>8 \mathrm{~cm}$ who underwent transumbilical single-port laparoscopicassisted adnexal surgery. In that study, 20 of the 22 cases were completed successfully, and cyst rupture only occurred in 2 cases $(10 \%)$.

We found that the operation time of the LESS-E group was significantly less than that of the LESS-I group $(\mathrm{P}=0.001)$. Conversely, Roh et al. (28) compared 43 cases of SPA-HALS with 96 cases of SPA-PLS for adnexal tumors and found that there was no statistically significant difference in the operation times between the 2 groups $(\mathrm{P}=0.947)$. The difference between these results and our results may be due to selection bias and the median tumor size being notably smaller in the SPA-PLS group than the SPA-HALS group (6.3 vs. $10.9 \mathrm{~cm} ; \mathrm{P}<0.001)$. Using the LESS-E approach, the cystic capsule was extracorporeally resected from the normal ovarian tissue, which enabled more precise dissection than the LESS-I approach. Further, the rapid remodeling of the ovarian tissue is possible in LESS-E approach, as in laparotomy, which significantly shortens the operation time.

Postoperative pain after laparoscopic surgery consists of incisional pain and deep abdominal (visceral) pain (29). The lower level of postoperative pain at 6 hours in patients who underwent LESS-E cystectomy might be due to the LESS-E cystectomy having a shorter incision expansion time than the LESS-I cystectomy. Furthermore, carbon dioxide pneumoperitoneum can cause postoperative shoulder pain due to phrenic nerve irritation (30). Once the detachable port cap was removed in the LESS-E cystectomy, the patient was turned to the supine position without pneumoperitoneum. Conversely, in the LESS-I group, pneumoperitoneum persisted throughout the operation. Thus, the LESS-E group had a lower VAS score at 6 hours after surgery. No statistically significant difference was found in VAS scores at 24 hours after surgery between the 2 groups due to the absorption of residual carbon dioxide. 
For the women in our study, who had a mean age of 28.90 years in the LESS-I group and 28.39 years in the LESS-E group, apart from an invisible scar, the preservation of fertility was also important. Mohamed et al. (31) reported that laparoscopic ovarian cystectomy, as compared to laparotomy, is associated with a significant reduction in the ovarian reserve. While the method of cyst enucleation and ovarian suture we use in LESS-E approach is the same as laparotomy, which can preserve normal ovarian tissues to the greatest extent. Further, as no coagulation of ovarian tissue was needed under direct vision, the damage to ovarian parenchyma and ovarian stromal blood vessels was decreased. Unfortunately, no anti-Mullerian hormone (AMH) test was conducted in our study that reflects ovarian function.

A previous study (32) described possible ovarian ligament damage during the process of the extracorporeal extraction of ovarian cysts through an umbilical incision. However, in another study, the author suggested that these tumors may be completely exteriorized through an umbilical incision because the pelvic peritoneum, adnexal ligaments, and salpinx become overstretched as tumors grow in size (28). We did not observe any injuries to the adnexal ligaments or tubes; however, such injuries are a risk of this approach, and we acknowledge that it is an important issue in the performance of this procedure. Thus, further research on LESS-E cystectomy with the mobilization of adnexal tumors needs to be conducted to analyze this risk.

The limitations of this study include its retrospective design, insufficient samples, and a lack of AMH results that made it impossible to evaluate changes in the ovarian reserve. Prospective studies need to be designed to further confirm the advantages of LESS-E cystectomy, which may benefit most women.

In conclusion, this is the first cohort study to compare LESS-E to LESS-I cystectomy in the treatment of benign ovarian cysts. LESS-E cystectomy is feasible and has comparable surgical results to those of LESS-I cystectomy. Further, no increase in perioperative complications was observed. More importantly, LESS-E cystectomy was found to be associated with a lower spillage rate and a reduced operation time in the selected women.

\section{Acknowledgments}

Funding: The study was funded by the National Key Technology R\&D Program of China (No. 2019YFC1005202), Chongqing Health Appropriate Technology promotion project (No. 2021jstg010) and a training program for clinical medical research in 2018 (No. 2018XLC3002).

\section{Footnote}

Reporting Checklist: The authors have completed the STROBE reporting checklist. Available at https://dx.doi. org/10.21037/atm-21-5625

Data Sharing Statement: Available at https://dx.doi. org/10.21037/atm-21-5625

Conflicts of Interest: All authors have completed the ICMJE uniform disclosure form (available at https://dx.doi. org/10.21037/atm-21-5625). The authors have no conflicts of interest to declare.

Ethical Statement: The authors are accountable for all aspects of the work in ensuring that questions related to the accuracy or integrity of any part of the work are appropriately investigated and resolved. All procedures performed in this study involving human participants were in accordance with the Declaration of Helsinki (as revised in 2013). The study was approved by the Ethics Committee of The First Affiliated Hospital, Army Medical University (Approval No. KY202024). Individual consent for this retrospective analysis was waived.

Open Access Statement: This is an Open Access article distributed in accordance with the Creative Commons Attribution-NonCommercial-NoDerivs 4.0 International License (CC BY-NC-ND 4.0), which permits the noncommercial replication and distribution of the article with the strict proviso that no changes or edits are made and the original work is properly cited (including links to both the formal publication through the relevant DOI and the license). See: https://creativecommons.org/licenses/by-nc-nd/4.0/.

\section{References}

1. Chong GO, Hong DG, Lee YS. Single-port (OctoPort) assisted extracorporeal ovarian cystectomy for the treatment of large ovarian cysts: compare to conventional laparoscopy and laparotomy. J Minim Invasive Gynecol 2015;22:45-9.

2. Canis M, Rabischong B, Houlle C, et al. Laparoscopic management of adnexal masses: a gold standard? Curr Opin Obstet Gynecol 2002;14:423-8. 
3. Medeiros LR, Stein AT, Fachel J, et al. Laparoscopy versus laparotomy for benign ovarian tumor: a systematic review and meta-analysis. Int J Gynecol Cancer 2008;18:387-99.

4. Medeiros LR, Rosa DD, Bozzetti MC, et al. Laparoscopy versus laparotomy for benign ovarian tumour. Cochrane Database Syst Rev 2009;(2):CD004751.

5. Jackson T, Einarsson J. Single-port gynecologic surgery. Rev Obstet Gynecol 2010;3:133-9.

6. Bedaiwy MA, Franjoine SE, Ali MK. Laparoendoscopic single-site (LESS) surgery in gynecology: Current status and future directions. Middle East Fertility Society Journal 2013;18:1-8.

7. Hoyer-Sørensen C, Vistad I, Ballard K. Is single-port laparoscopy for benign adnexal disease less painful than conventional laparoscopy? A single-center randomized controlled trial. Fertil Steril 2012;98:973-9.

8. Park JY, Kim DY, Kim SH, et al. Laparoendoscopic Single-site Compared With Conventional Laparoscopic Ovarian Cystectomy for Ovarian Endometrioma. J Minim Invasive Gynecol 2015;22:813-9.

9. Huang BS, Wang PH, Tsai HW, et al. Single-port compared with conventional laparoscopic cystectomy for ovarian dermoid cysts. Taiwan J Obstet Gynecol 2014;53:523-9.

10. Kavallaris A, Chalvatzas N, Hornemann A, et al. Laparoendoscopic single-site surgery (LESS) - is it feasible in gynecological surgery? Acta Obstet Gynecol Scand 2011;90:195-7.

11. Jung YW, Choi YM, Chung CK, et al. Single port transumbilical laparoscopic surgery for adnexal lesions: a single center experience in Korea. Eur J Obstet Gynecol Reprod Biol 2011;155:221-4.

12. Fagotti A, Fanfani F, Marocco F, et al. Laparoendoscopic single-site surgery for the treatment of benign adnexal diseases: a pilot study. Surg Endosc 2011;25:1215-21.

13. Kim WC, Lee JE, Kwon YS, et al. Laparoendoscopic single-site surgery (LESS) for adnexal tumors: one surgeon's initial experience over a one-year period. Eur J Obstet Gynecol Reprod Biol 2011;158:265-8.

14. Fagotti A, Fanfani F, Rossitto C, et al. Laparoendoscopic single-site surgery for the treatment of benign adnexal disease: a prospective trial. Diagn Ther Endosc 2010;2010:108258.

15. Escobar PF, Bedaiwy MA, Fader AN, et al. Laparoendoscopic single-site (LESS) surgery in patients with benign adnexal disease. Fertil Steril 2010;93:2074.e7-10.

16. Bedaiwy MA, Sheyn D, Eghdami L, et al. Laparoendoscopic single-site surgery for benign ovarian cystectomies. Gynecol Obstet Invest 2015;79:179-83.

17. Schmitt A, Crochet P, Knight S, et al. Single-Port Laparoscopy vs Conventional Laparoscopy in Benign Adnexal Diseases: A Systematic Review and Meta-Analysis. J Minim Invasive Gynecol 2017;24:1083-95.

18. Kim MS, Choi CH, Lee JW, et al. Comparison between Laparoendoscopic Single-Site and Conventional Laparoscopic Surgery in Mature Cystic Teratoma of the Ovary. Gynecol Minim Invasive Ther 2019;8:155-9.

19. Park JY, Kim DY, Suh DS, et al. Laparoendoscopic single-site versus conventional laparoscopic surgery for ovarian mature cystic teratoma. Obstet Gynecol Sci 2015;58:294-301.

20. Kim WC, Im KS, Kwon YS. Single-port transumbilical laparoscopic-assisted adnexal surgery. JSLS 2011;15:222-7.

21. Yi SW. Minimally invasive management of huge ovarian cysts by laparoscopic extracorporeal approach. Minim Invasive Ther Allied Technol 2012;21:429-34.

22. Song T, Kim MK, Kim ML, et al. Laparoendoscopic single-site surgery for extremely large ovarian cysts: a feasibility, safety, and patient satisfaction study. Gynecol Obstet Invest 2014;78:81-7.

23. Kim JS, Lee IO, Eoh KJ, et al. Surgical technique for single-port laparoscopy in huge ovarian tumors: SW Kim's technique and comparison to laparotomy. Obstet Gynecol Sci 2017;60:178-86.

24. Ki EY, Park EK, Jeong IC, et al. Laparoendoscopic Single Site Surgery for the Treatment of Huge Ovarian Cysts Using an Angiocatheter Needle. Yonsei Med J 2019;60:864-9.

25. Wang X, Li Y. Comparison of perioperative outcomes of single-port laparoscopy, three-port laparoscopy and conventional laparotomy in removing giant ovarian cysts larger than $15 \mathrm{~cm}$. BMC Surg 2021;21:205.

26. Smorgick N, Barel O, Halperin R, et al. Laparoscopic removal of adnexal cysts: is it possible to decrease inadvertent intraoperative rupture rate? Am J Obstet Gynecol 2009;200:237.e1-3.

27. Goh SM, Yam J, Loh SF, et al. Minimal access approach to the management of large ovarian cysts. Surg Endosc 2007;21:80-3.

28. Roh HJ, Lee SJ, Ahn JW, et al. Single-port-access, handassisted laparoscopic surgery for benign large adnexal tumors versus single-port pure laparoscopic surgery for adnexal tumors. Surg Endosc 2012;26:693-703.

29. Li Y, Dou Z, Yang L, et al. Oxycodone versus other opioid analgesics after laparoscopic surgery: a meta-analysis. Eur J Med Res 2021;26:4. 


\section{Page 10 of 10}

30. Donmez T, Erdem VM, Uzman S, et al. Laparoscopic cholecystectomy under spinal-epidural anesthesia vs. general anaesthesia: a prospective randomised study. Ann Surg Treat Res 2017;92:136-42.

31. Mohamed ML, Nouh AA, El-Behery MM, et al. Effect on ovarian reserve of laparoscopic bipolar electrocoagulation versus laparotomic hemostatic

\section{Tan et al. LESS-E vs. LESS-I approach in cystectomy}

sutures during unilateral ovarian cystectomy. Int J Gynaecol Obstet 2011;114:69-72.

32. Takeda A, Imoto S, Mori M, et al. Isobaric laparoendoscopic single-site surgery with wound retractor for adnexal tumors: a single center experience with the initial 100 cases. Eur J Obstet Gynecol Reprod Biol 2011;157:190-6.

Cite this article as: Tan W, Tang S, Yao Y, Deng Y, Zhong K, Liang Z, Deng L, Wang Y. Perioperative outcomes of laparoendoscopic single-site extracorporeal versus intracorporeal cystectomy for benign ovarian cysts: a retrospective cohort study based on propensity score matching. Ann Transl Med 2021;9(23):1725. doi: 10.21037/atm-21-5625 